\title{
ANALISIS KETIDAKSEIMBANGAN BEBAN PADA GARDU DISTRIBUSI KA 2085 DI PT. PLN (Persero) DISTRIBUSI BALI RAYON MENGWI BADUNG
}

\author{
R. Suputra ${ }^{1}$, A. I. Weking ${ }^{2}$, W. Rinas ${ }^{3}$ \\ Jurusan Teknik Elektro, Fakultas Teknik, Universitas Udayana Denpasar - Bali \\ Email : r.suputra@yahoo.com ${ }^{1}$, tony@ee.unud.ac.id $^{2}$, $\underline{\text { rinas@ee.unud.ac.id }}^{\underline{3}}$
}

\begin{abstract}
Abstrak
Perbedaan nilai arus yang mengalir pada tiap penghantar fasa pada suatu jaringan distribusi tenaga listrik, menyebabkan keadaan tidak seimbang. Keadaan tidak seimbang pada suatu jaringan tenaga listrik akan mengakibatkan terjadinya peningkatan rugi daya Penelitian ini dilakukan dengan menitikberatkan rugi daya keadaan seimbang dan keadaan tak seimbang saat kondisi beban puncak di JTR dan SR gardu distribusi KA 2085, ketidakseimbangan beban pada jaringan distribusi sekunder KA 2085 telah menyebabkan terjadinya rugi-rugi daya beban seimbang kondisi beban puncak sebesar $0,104 \mathrm{~kW}$ dengan prosentase rugi-rugi sebesar $0,33 \%$. Namun rugi daya di beban tak seimbang keadaan beban puncak sebesar 0,211 kW dengan prosentase rugi daya senilai $0,69 \%$.
\end{abstract}

Kata Kunci: beban seimbang dan tidak seimbang, rugi-rugi daya, jaringan distribusi, gardu distribusi

\begin{abstract}
The difference in the value of the current flowing in each phase conductor in a power distribution network, causes an unbalanced state. The unbalanced state of a power grid will result in an increase in power losses. This study is conducted by analyzing balanced state power losses and unbalanced state under peak load conditions at JTR and SR of K8585 distribution relay, unbalance burden on secondary distribution network KA 2085 has resulted in the loss of load-balanced power of peak load time of $0.104 \mathrm{~kW}$ with a loss-loss prosenase of $0.33 \%$. While the losses for unbalanced load peak load time of $0.211 \mathrm{~kW}$ with a percentage loss of $0.69 \%$.
\end{abstract}

Keywords: balanced and unbalanced load, power loss, distribution network, distribution substation

\section{PENDAHULUAN}

Transformator KA 2085 ini menyediakan Daya listrik kepada konsumen PT. PLN di wilayah banjar Padang Bali desa Dalung.

Pemakaian daya listrik yang tidak merata, akan mengakibatkan timbulnya ketidakseimbangan arus yang mengalir pada tiap hantaran fasanya. Terbukti pada gardu distribusi KA 2085 dimana pembebanan pada setiap fasanya adalah sebesar: untuk $\mathrm{R}=31$ Ampere, $\mathrm{S}=14$ Ampere, $\mathrm{T}=50$ Ampere, dan kawat Netral $=42$ Ampere.

ketidakseimbangan beban adalah salah satu faktor yang mengakibatkan rugirugi daya pada saluran [1].

Selanjutnya harus dilakukan kajian tentang pengaruh ketidakseimbangan beban terhadap rugi-rugi daya pada transformator distribusi KA 2085, yang mengacu pada permasalahan yang didapat. Dan diadakanlah penelitian yang seperti dibawah ini.

\section{TINJAUAN PUSTAKA}

\subsection{Impedansi Saluran}

Konduktor akan selalu memiliki resistansi dan reaktansi. Gabungan diantara keduanya disebut impedansi

\subsubsection{Resistansi} [5]. 


$$
R=\rho \frac{l}{A}
$$

Definisi :

$R$ : resistansi (Ohm)

$\rho$ : tahanan jenis kawat (Ohm. mm ${ }^{2} / \mathrm{m}$ )

$l$ : panjang kawat (meter)

$A$ : luas penampang kawat $\left(\mathrm{mm}^{2}\right)$

\subsubsection{Reaktansi}

Reaktansi penghantar untuk jaringan distribusi pada dasarnya terdiri dari induktansi, maka reaktansinya disebut reaktansi induktif $\left(X_{L}\right)$.

$$
X_{L}=2 \pi f L
$$

Definisi :

$X_{L}$ : reaktansi jaringan $(\mathrm{Ohm})$

$f$ : frekuensi jaringan $(\mathrm{Hz})$

$L$ : induktansi (Henry)

\subsubsection{Arus Beban Penuh Transforma- tor}

Daya transformator apabila dilihat dari sisi tegangan tinggi dapat dihitung dengan Persamaan 5 [7].

$$
S=V . I
$$

Definisi :

$S$ : daya transformator ( $k V A$ )

$V$ : tegangan sisi primer trafo $(\mathrm{kV})$

$I$ : arus jala-jala (A)

Selanjutnya untuk menghitung arus beban penuh transformator (full load) dapat menggunakan Persamaan 6 [6].

$$
I_{F L}=\frac{S}{\sqrt{3} \cdot V}
$$

$$
I_{\text {rata-rata }}=\frac{I_{R}+I_{S}+I_{T}}{3}
$$

\section{Definisi :}

Irata-rata: arus ketiga fasa (Ampere)

$I_{R}:$ arus fasa $\mathrm{R}$ (Ampere)

IS : arus fasa $\mathrm{S}$ (Ampere)

$I_{T}$ : arus fasa $\mathrm{T}$ (Ampere)

Prosentase beban transformator, dapat dijumlahkan :

$$
\% \text { pembebanan }=\frac{I_{\text {rata-rata }}}{I_{F L}} \times 100 \%
$$

(8)

\subsubsection{Ketidakseimbangan Beban \\ Transformator}

Pada saluran daya dalam keadaan tidak seimbang, besarnya arus tiap fasa dapat dinyatakan dengan koefisien $a$, $b$, dan c.

Pada keadaan seimbang (1) sama besarnya arus rata-rata $\left(I_{\text {rata }}\right)$

$$
\begin{aligned}
& I_{R}=a . I_{\text {rata-rata maka }:} a=\frac{I_{R}}{I_{\text {rata-rata }}} \\
& I_{S}=b . I_{\text {rata-rata maka: }} b=\frac{I_{S}}{I_{\text {rata-rata }}}
\end{aligned}
$$

\section{METODE PENELITIAN}

Data yang dipakai didalam analisis tugas akhir ini berasal dari data primer yang diperoleh dari hasil pengukuran langsung disetiap pelanggan PT.PLN (Persero) Area Bali Selatan Rayon Mengwi pada Gardu KA 2085.

Tahapan analisis yang dilakukan :

1. Pengumpulan dan pengolahan data beban masing-masing pelanggan PT. PLN (Persero) Rayon Mengwi yang bersumber dari gardu distribusi KA 2085,

2. Rekapitulasi nilai beban tiap jurusan JTR berdasarkan data beban masingmasing pelanggan.

Definisi :

$I_{F L}:$ arus beban penuh $(A)$

$S$ : daya trafo $(k V A)$ 


\section{HASIL DAN PEMBAHASAN}

\subsection{Sistem Kelistrikan di JTR KA 2085}

Sistem arus listrik JTR KA 2085 memiliki data teknis seperti dibawah [9].
1. Arus Beban : 48,8 kVA.
2. Total Konsumen
: 22 Pelanggan
3. Pola JTR
: System Radial.
4. Total Jurusan
: Dua Jurusan.
5. Panjang kabel$$
\text { : 274,1 m. }
$$$$
554,65 \mathrm{~m}
$$
6. Macam Penghantar: LVTC (JTR) NFA2XX (SR).

Maka diperoleh data pengukuran saat beban puncak seperti yang terlihat di Tabel 1.

Tabel 1. Hasil pengukuran beban tiap pelanggan

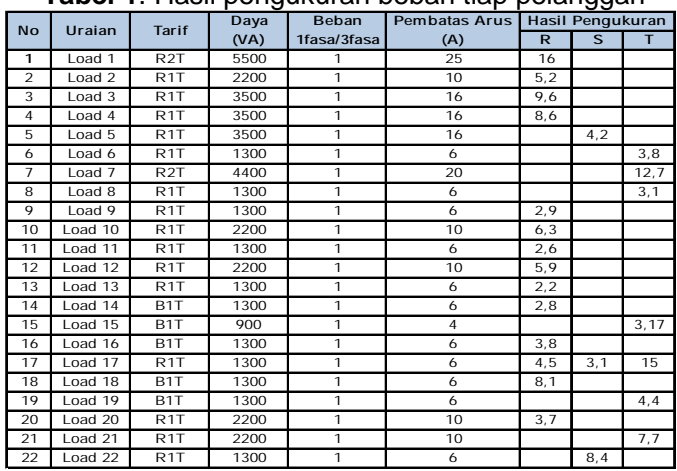

Setiap Jurusan JTR seperti pada Tabel 2 berikut :

Tabel 2. Rekapitulasi beban tiap jurusan

\begin{tabular}{|c|c|c|c|c|c|c|}
\hline \multirow{2}{*}{ No } & \multicolumn{2}{|c|}{ Uraian } & \multicolumn{3}{c|}{ Data Beban (A) } & \multirow{2}{*}{ Panjang (m) } \\
\cline { 2 - 6 } & Jurusan A & Jurusan C1 & R & S & T & \\
\hline 1 & JTR 4 & & 9,2 & & & 33,1 \\
\hline 2 & JTR 3 & & 8,6 & 4,2 & 3,1 & 50,1 \\
\hline 3 & JTR 2 & & 9,6 & & 16,5 & 45,7 \\
\hline 4 & JTR 1 & & 21,2 & & & 34,2 \\
\hline 5 & & JTR 5 & 8,1 & & & 35 \\
\hline 6 & & JTR 6 & 3,7 & 8,4 & 7,7 & 28 \\
\hline 7 & & JTR 7 & & & & 22 \\
\hline 8 & & JTR 8 & & & 4,4 & 26 \\
\hline
\end{tabular}

kemudian diakumulasikan seperti tertera dalam Tabel 3

Tabel 3. Rekapitulasi hasil pengukuran

\begin{tabular}{|c|c|c|c|c|}
\hline \multirow{3}{*}{ Kondisi } & \multicolumn{4}{|c|}{ Hasil Pengukuran } \\
\cline { 2 - 5 } & \multirow{2}{*}{ Tegangan (V) } & \multicolumn{3}{|c|}{ Daya(VA) } \\
\cline { 3 - 5 } & & $\mathbf{R}$ & $\mathbf{S}$ & $\mathbf{T}$ \\
\hline Beban Puncak & 235 & 82,2 & 12,6 & 34,87 \\
\hline
\end{tabular}

Tabel 4. Total Daya JTR

\begin{tabular}{|c|c|c|c|c|c|}
\hline \multirow{3}{*}{ Kondisi } & \multicolumn{4}{|c|}{ Hasil Pengukuran } & \multirow{2}{*}{$\begin{array}{c}\text { Total Beban } \\
\text { (kVA) }\end{array}$} \\
\cline { 2 - 5 } & Tegangan & \multicolumn{3}{|c|}{ Daya (VA) } & R+S+T \\
\cline { 2 - 5 } & $\mathbf{( V )}$ & $\mathbf{R}$ & $\mathbf{S}$ & $\mathbf{T}$ & $\mathbf{2}$ \\
\hline Beban Puncak & 235 & 82,2 & 12,6 & 34,87 & 30,47 \\
\hline
\end{tabular}

\subsection{Persentase Pembebanan Trans- formator}

Aliran Daya beban penuh pada trafo dijumlahkan memakai Persamaan 6, dengan perhitungan sebagai berikut.

$$
I_{F L}=\frac{S}{\sqrt{3} V}=\frac{160000}{\sqrt{3} .400}=230,9 \mathrm{~A}
$$

Maka:

$$
\begin{aligned}
& I_{\text {rata-rata }}=\frac{I_{R}+I_{S}+I_{T}}{3} \\
& =\frac{82,2+12,6+34,87}{3}=43,2 \mathrm{~A}
\end{aligned}
$$

Prosentase beban trafor dijumlahkan dengan memakai Persamaan 8, dengan perhitungan seperti dibawah.

$$
\begin{aligned}
\% \text { pembebanan } & =\frac{I_{\text {rata-rata }}}{I_{F L}} \times 100 \% \\
& =\frac{43,2}{230,9} \times 100 \% \mid \\
& =18,7 \%
\end{aligned}
$$

Berdasarkan hasil perhitungan di atas, didapatkan hasil beban trafo waktu beban puncak sebesar $18,7 \%$.

\subsection{Prosentase Beban tidak seimbang}

Prosentase tidak seimbanganya beban trafo dijumlahkan memakai Persamaan sembilan, sepuluh, dan sebelas

Rata-rata ketidakseimbangan beban:

$$
\begin{aligned}
& =\frac{\{|a-1|+|b-1|+|c-1|\}}{3} \times 100 \% \\
& =\frac{\{|1,9-1|+|0,3-1|+|0,8-1|\}}{3} \times 100 \% \\
& =\frac{\{|0,9|+|0,7|+|0,2|\}}{3} \times 100 \% \\
& =60 \%
\end{aligned}
$$




\subsection{Analisis Rugi Daya JTR KA 2085 4.4.1 Analisis Pada Kondisi Beban Seimbang}

Rugi daya pada penghantar JTR kondisi seimbang, dihitung dengan perhitungan seperti dibawah:

Daya losses pada penghantar JTR 1.

$$
\begin{aligned}
& I_{I I R I}=I_{J R R I} \\
& I_{\text {rata-rata } J I R I}=7,07 \mathrm{~A} \\
& L_{\text {JIRI }}=34,2 \text { meter }=0,03 \mathrm{~km} \\
& R_{\text {IRI }}=0,5155 \mathrm{Ohm} / \mathrm{km} \\
& =0,5096 \cdot 0,03 \\
& =0,017 \mathrm{Ohm} \\
& \triangle P_{J T R I}=3 \cdot I^{2} \cdot R \\
& =3 \cdot 7,07^{2} \cdot 0,017 \\
& =2,54 \text { Watt }
\end{aligned}
$$

Sehingga diperoleh analisis daya losses semua penghantar JTR yang lain pada masing-masing jurusan seperti Tabel 5.

Tabel 5. Daya losses beban seimbang pada penghantar JTR

\begin{tabular}{|c|c|c|c|c|c|c|}
\hline \multirow{2}{*}{ No } & \multicolumn{2}{|c|}{ Uraian } & \multicolumn{2}{|c|}{ Data Beban (A) } & \multirow{2}{*}{ Rugi-rugi Daya (W) } \\
\cline { 2 - 6 } & Jurusan A & Jurusan C1 & R & S & T & \\
\hline 1 & JTR 4 & & 9,2 & & 3,1 & 2,54 \\
\hline 2 & JTR 3 & & 8,6 & 4,2 & 16,5 & 7,36 \\
\hline 3 & JTR 2 & & 9,6 & & & 30,73 \\
\hline 4 & JTR 1 & & 21,2 & & & 29,46 \\
\hline 5 & & JTR 5 & 8,1 & & & 6,2 \\
\hline 6 & & JTR 6 & 3,7 & 8,4 & 7,7 & 1,86 \\
\hline 7 & & JTR 7 & & & & 0,072 \\
\hline 8 & \multicolumn{7}{|c|}{ JTR 8 } & & & 4,4 & 0,083 \\
\hline \multicolumn{7}{|c|}{} \\
\hline
\end{tabular}

Hasil akumulasi pada Tabel 5 di atas, total rugi-rugi daya beban seimbang pada penghantar JTR sebesar 78,305 Watt $\approx$ 0,078305 kW..

Rugi-rugi daya yang ada di SR dapat

\begin{tabular}{|c|c|c|c|c|c|}
\hline \multirow{2}{*}{ No } & \multirow{2}{*}{ Uraian } & \multicolumn{3}{|c|}{ Data beban (A) } & \multirow[b]{2}{*}{ Rugi-rugi Daya (W } \\
\hline & & $\mathbf{R}$ & $\mathrm{s}$ & $T$ & \\
\hline 1 & SR 1 & 16 & & & 8,29 \\
\hline 2 & SR 2 & 5,2 & & & 0,139 \\
\hline 3 & SR 3 & 9,9 & & & 1,32 \\
\hline 4 & SR 4 & 8,6 & & & 1,1 \\
\hline 5 & SR 5 & & 4,2 & & 0,64 \\
\hline 6 & SR 6 & & & 3,8 & 0,195 \\
\hline 7 & SR 7 & & & 12,7 & 6,36 \\
\hline 8 & SR 8 & & & 3,1 & 0,203 \\
\hline 9 & SR 9 & 2,9 & & & 0,128 \\
\hline 10 & SR 10 & 6,3 & & & 0,768 \\
\hline 11 & SR 11 & 2,6 & & & 0,359 \\
\hline 12 & SR 12 & 5,9 & & & 2,62 \\
\hline 13 & SR 13 & 2,2 & & & 0,103 \\
\hline 14 & SR 14 & 2,8 & & & 0,145 \\
\hline 15 & SR 15 & & & 3,17 & 0,089 \\
\hline 16 & SR 16 & 3,8 & & & 0,219 \\
\hline 17 & SR 17 & 4,5 & & & 0,507 \\
\hline 18 & SR 18 & 8,1 & & & 0,629 \\
\hline 19 & SR 19 & & & 4,4 & 0,391 \\
\hline 20 & SR 20 & 3,7 & & & 0,15 \\
\hline 21 & SR 21 & & & 7,7 & 1,61 \\
\hline 22 & SR 22 & & 8,4 & & 0,658 \\
\hline & & & & Total & 26,623 \\
\hline
\end{tabular}
ditinjau melalui, daya losses untuk penghantar SR1.

$$
\begin{aligned}
I_{S R 1} & =I_{S R 1}+I_{S R 2} \\
I_{\text {rata }- \text { rataSR } 1} & =7,06 \mathrm{~A} \\
L_{S R 1} & =25,016 \text { meter }=0,025 \mathrm{~km} \\
R_{S R 1} & =2,2189 \text { Ohm } / \mathrm{km} \\
& =2,2189 \cdot 0,025 \\
& =0,055 \mathrm{Ohm} . \\
\Delta P_{S R 1}=3 . & I^{2} \cdot R \\
& =3 \cdot 7,06^{2} \cdot 0,055 \\
& =8,29 \text { Watt. }
\end{aligned}
$$

\begin{tabular}{|c|c|c|c|}
\hline \multirow[t]{2}{*}{ Kondisi } & \multicolumn{2}{|c|}{$\begin{array}{c}\text { Rugi-rugi Daya } \\
\text { Pada Saluran (W) }\end{array}$} & \multirow{2}{*}{$\begin{array}{c}\text { Total } \\
\text { Rugi-rugi Daya } \\
\text { (W) }\end{array}$} \\
\hline & JTR & SR & \\
\hline Beban Puncak & 78,305 & 26,623 & 104,928 \\
\hline
\end{tabular}

Hasil penghitungan yang sama dengan penghantar SR1, dapat dianalisis untuk seluruh penghantar SR dengan jumlah 22 penghantar seperti pada Tabel 6 .
Tabel 6. Daya losses beban seimbang pada

Total daya losses beban seimbang pada penghantar SR sebesar 26,626 Watt $\approx$ $0,026623 \mathrm{~kW}$.

Daya losses total dengan pada kondisi seimbang untuk JTR dan SR dapat dilihat pada Tabel 7.

Tabel 7. Total Rugi daya beban seimbang

Saluran kepada keadaan beban puncak apabila disebutkan pada keadaan yang didalam prosentase: $\%$ rugi - rugi $=\frac{\text { total rugi daya pada saluran }(k W)}{\text { daya dari } P L N(k V A)} \times 100 \%$

$$
\begin{gathered}
=\frac{0,10}{30,47} \times 100 \% \\
=0,33 \%
\end{gathered}
$$

\subsubsection{Analisis Pada Kondisi Beban Tidak Seimbang}

Daya losses beban tidak seimbang pada penghantar JTR, dihitung dengan Persamaan 13 dengan cara.

Rugi-rugi daya untuk penghantar JTR 1: 


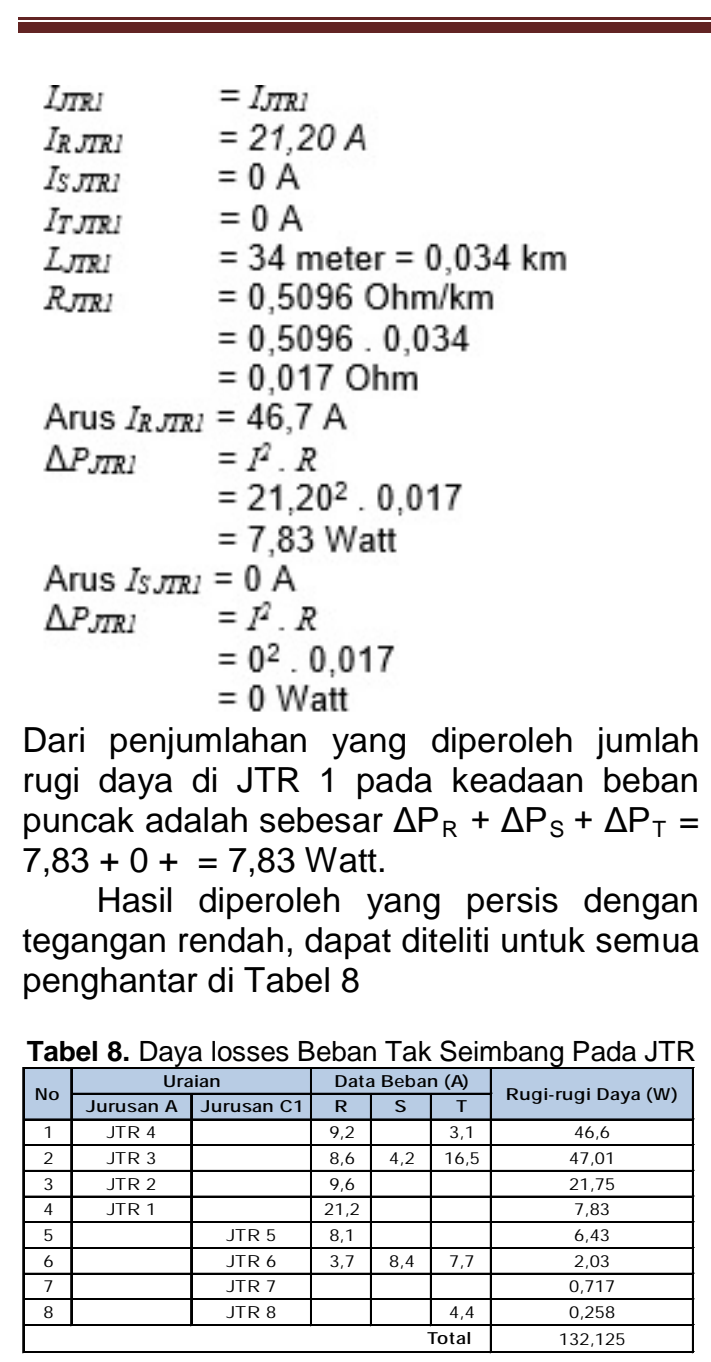

Akumulasi pada Tabel 8 di atas, total rugi daya beban tak seimbang dipenghantar JTR sebesar 132,12 Watt $\approx 0,13212 \mathrm{~kW}$.

Daya losses yang terletak dipenghantar SR kondisi tak seimbang: penghantar SR1.

$$
\begin{aligned}
& I_{S R I}=I_{S R I}+I_{S R 2} \\
& I_{R S R I}=21,20 \mathrm{~A} \\
& \text { ISSRI } \quad=0 \mathrm{~A} \\
& I_{T S R I} \quad=0 \mathrm{~A} \\
& L_{S R I} \quad=25,016 \text { meter }= \\
& 0,025 \mathrm{~km} \\
& R_{S R I} \quad=2,2189 \mathrm{Ohm} / \mathrm{km} \\
& =2,2189 \cdot 0,025 \\
& =0,055 \mathrm{Ohm}
\end{aligned}
$$

maka :

$$
\begin{array}{ll}
\text { Arus } I_{R S R 1} & =21,20 \mathrm{~A} \\
\triangle P_{S R 1} & =I^{2} \cdot R \\
& =21,20^{2} \cdot 0,055 \\
& =24,94 \text { Watt } \\
\text { Arus } I_{S S R 1} & =0 \mathrm{~A}
\end{array}
$$

$$
\begin{array}{ll}
\Delta P_{S R I} & =I^{2} \cdot R \\
& =0^{2} \cdot 0,055 \\
& =0 \text { Watt } \\
\text { Arus } I_{R S R I} & =0 \mathrm{~A} \\
\Delta P_{S R I} & =I^{2} \cdot R \\
& =0^{2} \cdot 0,055 \\
& =0 \text { Watt }
\end{array}
$$

Nilai yang diperoleh sama dengan SR1, dapat dijabarkan untuk setiap penghantar dengan banyaknya total 22 penghantar, seperti pada Tabel 9.

Tabel 9. Total Daya losses Penghantar SR Beban Tak

\begin{tabular}{|c|c|c|c|c|c|}
\hline \multirow{2}{*}{ No } & \multirow{2}{*}{ Uraian } & \multicolumn{3}{|c|}{ Data beban (A) } & Rugi-rugi Daya (W) \\
\cline { 3 - 6 } & & R & S & T & \\
\hline 1 & SR 1 & 16 & & & 24,94 \\
\hline 2 & SR 2 & 5,2 & & & 0,41 \\
\hline 3 & SR 3 & 9,9 & & & 4 \\
\hline 4 & SR 4 & 8,6 & & & 3,3 \\
\hline 5 & SR 5 & & 4,2 & & 1,98 \\
\hline 6 & SR 6 & & & 3,8 & 0,6 \\
\hline 7 & SR 7 & & & 12,7 & 19,4 \\
\hline 8 & SR 8 & & & 3,1 & 0,614 \\
\hline 9 & SR 9 & 2,9 & & & 0,4 \\
\hline 10 & SR 10 & 6,3 & & & 2,304 \\
\hline 11 & SR 11 & 2,6 & & & 1,102 \\
\hline 12 & SR 12 & 5,9 & & & 8 \\
\hline 13 & SR 13 & 2,2 & & & 0,311 \\
\hline 14 & SR 14 & 2,8 & & & 0,44 \\
\hline 15 & SR 15 & & & 3,17 & 0,28 \\
\hline 16 & SR 16 & 3,8 & & & 0,665 \\
\hline 17 & SR 17 & 4,5 & & & 0,338 \\
\hline 18 & SR 18 & 8,1 & & & 1,88 \\
\hline 19 & SR 19 & & & 4,4 & 1,18 \\
\hline 20 & SR 20 & 3,7 & & & 0,453 \\
\hline 21 & SR 21 & & & 7,7 & 4,85 \\
\hline 22 & SR 22 & & 8,4 & & 2 \\
\hline
\end{tabular}

Daya losses total pada saat keadaan beban tak seimbang untuk JTR dan SR dapat dilihat di Tabel 10.

Tabel 10. Total Daya Losses Tak Seimbang

\begin{tabular}{|c|c|c|c|}
\hline \multirow{2}{*}{ Kondisi } & \multicolumn{2}{|c|}{$\begin{array}{c}\text { Rugi Daya Beban } \\
\text { Pada Saluran (M) }\end{array}$} & $\begin{array}{c}\text { Total } \\
\text { Rugi-rugi Daya } \\
\text { (M) }\end{array}$ \\
\cline { 2 - 3 } & JTR & SR & 211,57 \\
\hline Beban Puncak & 132,125 & 79,447 & 227 \\
\hline
\end{tabular}

Besarnya nilai rugi daya beban tak seimbang saluran saat keadaan beban tak seimbang jika disebutkan dalam prosentase ialah :

$$
\begin{aligned}
\% \text { rugi }- \text { rugi }=\frac{\text { total rugi daya pada saluran }(k W)}{\text { daya dari } P L N(k V A)} \times 100 \% \\
=\frac{0,211}{30,47} \times 100 \% \\
=0,69 \%
\end{aligned}
$$

\subsection{Nilai Perbandingan Rugi-Rugi Daya}

beban seimbang dan tidak seimbang saat kondisi beban puncak dapat dilihat pada Tabel 14. 


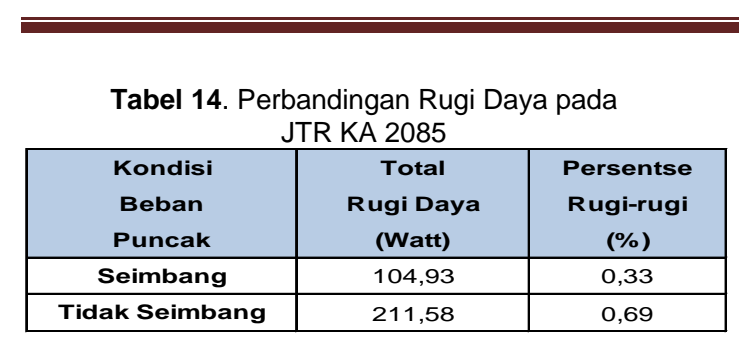

\section{KESIMPULAN}

Setelah dilakukan perhitungan dari data beban pada gardu distribusi KA 2085, prosentase pembebanan transformator pada waktu beban puncak ialah sebesar $18,7 \%$. Persentase pada ketidakseimbangan beban adalah sebesar 60

Ketidakseimbangan beban yang terjadi digardu distribusi KA2085 menyebabkan Daya losses waktu beban puncak pada kondisi beban seimbang $0,104 \mathrm{~kW}(0,33 \%)$ dan $0,211(0,69 \%)$ untuk keadaan beban tak seimbang.

\section{DAFTAR PUSTAKA}

[1] Setiadji, 2006. Pengaruh Ketidakseimbangan Beban Terhadap Arus Netral Dan Losses Pada Trafo Distribusi. Jurnal Teknik Elektro, Volume 6, No. 1.

[2] Arismunandar, A, 1991. Buku Pegangan Tenaga Listrik - Gardu Induk. Jakarta : PT. Pradnya Paramita.

[3] Barnett. H. G and Parsons. J. S, 1950 Elektrical Transmission Distribution Reference Book.Pennsylvania - USA : Westinghouse Electric Corporation.

[4] Gonen. T, 1986. Electric Power Distribution System Engineering. USA : McGraw - Hill.

[5] Grainger. J. J dan Stevenson, Jr. W. D, 1994. Power System Analisys. USA : McGraw - Hill.

[6] Pansini. Antony J. E. E., P. E. 2006. Electrical Distribution Engineering, 3rd Edition. Georgia - USA : The Fairmont Press, Inc.

[7] John. J, Winers. Jr, 2002. Power Transformers Principles and Applications. Pannsylvania : Marcel Dekker. Inc.

[8] Suhadi, 2008. Teknik Distribusi Tenaga Listrik Jilid 1. Jakarta : Direktorat Pembinaan Sekolah Kejuruan, Departemen Pendidikan Nasional.
[9] Data Pelanggan JTR KA 2085 PT. PLN (Persero) Distribusi Bali Rayon Mengwi. 